\title{
MULHERES E POLÍTICA DO CUIDADO EM TEMPOS DE COVID-19
}

\author{
Mariane de Oliveira Biteti ${ }^{1}$ \\ Universidade do Estado do Rio de Janeiro \\ bitetimariane@gmail.com
}

\section{RESUMO:}

Esse texto parte de uma reflexão sobre alguns exemplos de políticas de Estado liderados por mulheres que, até o momento, obtiveram sucesso no controle e combate à propagação do novo coronavírus. Desenvolvemos a nossa hipótese como parte da compreensão do que pode ser uma agenda política feminista. Para tanto, supomos ser importante aprender e potencializar as experiências das mulheres da margem, e tudo o que elas agenciam de ética e política do cuidado, como mecanismos de preservação da vida.

Palavras-chave: Mulher; Política do cuidado; Escala; Feminismo.

Todo o mundo está sofrendo com a Covid-19. Sofrendo pelas questões da vida cotidiana, tão diretamente afetadas pelo necessário isolamento social: convívio, trabalho, família; elementos que constituem a nossa rede de sociabilidades e de afetos. Sofremos com a percepção da desigualdade, que ainda que sejamos sensíveis a ela, mostra sua face mais violenta quando se decide, pelos critérios da raça, da classe, do gênero e da idade, quem pode viver e quem deve morrer, um mix nefasto de biopolítica, necropolítica e darwinismo social.

Muitas reflexões e muitas projeções estão sendo feitas, muitos textos estão sendo escritos, há um horizonte a ser perseguido? Certamente há muitos, e haverá disputas sobre o que e quem irá pautar o rumo dos nossos destinos, sejam eles afetivos e sociais, sejam eles geopolíticos e econômicos. Mesmo porque, tudo isso se encontra de muitas maneiras na produção do nosso ser social. Seremos mais solidários e colaborativos? Não, se o capitalismo neoliberal militarizado colonial, continuar sendo o contexto que governa as relações da globalização. Sairemos como dessa, se todo o aparato tecnológico de controle e vigilância for implantado de vez e de rompante no nosso cotidiano, como uma mediação das relações

\footnotetext{
${ }^{1}$ Professora do Departamento de Geografia e do Programa de Pós-Graduação em Geografia da Universidade do Estado do Rio de Janeiro - Faculdade de Formação de Professores (UERJ/FFP) - São Gonçalo (RJ). 
sociais? Há muitas perguntas, aqui existem poucas até, porque o objetivo desse texto é trazer o protagonismo de uma outra pergunta, vejamos.

O que existe em comum na política de países como Alemanha, Nova Zelândia, Finlândia, Dinamarca, Islândia e Bélgica, que tem feito com que esses países sejam reconhecidos hoje, como referências no combate à Covid-19? Não vou responder com protocolos médicos, medidas emergenciais, políticas sociais, certamente tudo isso foi feito nos países em questão, lembrando, sobretudo, que vários desses ficam geograficamente próximos a Espanha, Itália e França, locais onde o número de mortos é aviltante sem que sequer tenham atingido o pico dos casos no momento em que escrevo. A resposta que mobiliza um conjunto de outras perguntas, mas mediada pela evidência inicial é que todos esses países são chefiados por mulheres, são elas: Angela Merkel, Jacinda Ardern, Sanna Marin, Helle Thorning-Schmidt, Katrín Jakobsdóttir e Sophie Wilmès.

Não estamos aqui fazendo uma defesa ampla ou uma análise rigorosa de cada um desses governos, sabemos que há controvérsias nas relações de alguns desses países em suas políticas econômicas internacionais, tal como a Alemanha da Merkel. Porém, supomos, diante da pandemia que vivemos, saber quais as implicações que essa constatação pode trazer, e o que isso pode representar de perspectiva futura para o mundo, se poderemos ou não afirmar um devir-mulher. Diante disso, qual espectro de devir-mulher irá pautar a política mundial pós-coronavírus, um devir-mulher inspirado pela concepção, podemos dizer, de abertura e transformação em Deleuze e Guatarri (2011) ou um devir-mulher inspirado pelo sentido, podemos dizer, de reprodução das marcas negativas do racismo e das desigualdades do devirnegro em Achille Mbembe (2017)?

Em coluna publicada recentemente, Nina Lemos ${ }^{2}$ faz uma advertência de sentido contrário, mas dialeticamente articulada a nossa, quando afirma que as posturas tomadas por Boris Johnson na Inglaterra, Donald Trump nos EUA e Jair Bolsonaro, no Brasil, são exemplos de como um certo sentido de masculinidade pode matar. Os três assumiram um discurso negacionista, pelo menos a princípio, que afetou o modo da condução das políticas de contenção à disseminação do vírus nos países chefiados por eles. A despeito das diferenças

\footnotetext{
${ }^{2}$ Disponível em: <https://ninalemos.blogosfera.uol.com.br/2020/03/30/bolsonaro-trump-e-a-masculinidadetoxica-que-pode-matar/>. Acessado em: 10 de abril de 2020. 
que se dão posteriormente, seja em razão das causas internas ou pressões externas, o fato é que ficou explícito um comportamento típico do que definimos como masculinidade tóxica e que, a propósito desse texto, iremos chamar de política anti-cuidado. Obviamente, há muitos outros aspectos que explicam esses posicionamentos, mas concordamos que um deles é esse que Nina Lemos analisa, utilizando os dados de uma pesquisa da Organização Pan-Americana de Saúde em relação ao comportamento de risco assumido pelos homens, como indicativo da sua masculinidade. Nesse caso, diante da Covid-19, um risco que criminosamente dividem com toda a sociedade.

O feminismo tem se debruçado nos últimos tempos em debates sobre a ética ou a política do cuidado, mas talvez faltasse um elemento que desse a um conjunto de textos importantes sobre o tema, referências de outras escalaridades, para além do lar e da comunidade, reproduzindo o tema à luz da sua expressividade global. Supomos que a disseminação do novo coronavírus como uma pandemia e as iniciativas consideradas de sucesso entre as lideranças femininas possam projetar um certo sentido de política feminista, inspirada em outra concepção da relação sociedade-natureza, e em outra concepção das relações humanas pautadas pelo cuidado com o outro.

Quando aqui falamos em um "certo sentido de política feminista", nosso objetivo é o de ser cautelosos, visto que a liderança institucional feminina não significa expressamente que haverá uma incorporação de pautas feministas às práticas implementadas por essas mulheres de Estado. Ainda que as suas posições possam ser resultadas de construções, em parte certamente protagonizadas pelas lutas feministas, seriam elas eminentemente feministas ou vocalizadoras de pautas que possam ser assim identificadas? Seria necessário acompanhar esse movimento realçado pelas políticas de prevenção, acolhimento e gestão que marcam as iniciativas dessas mulheres, para buscar entender se há um reconhecimento disso como uma política feminista, se essas iniciativas podem ou não se desdobrarem em outras, num porvir feminista da política nacional.

No que tange ao tema do cuidado, que tomamos aqui como um tema do feminismo, alçado a uma categoria da práxis dessas mulheres, ele não ocorre sem conflitos dentro do próprio feminismo. Afinal, atribuir uma característica como algo que define o gênero, pode sim ser uma abordagem essencialista, e isso só faria sentido para algumas feministas, como 
Spivak (1985, 2019), se denotasse uma identidade acionada como estratégia de luta, um "essencialismo estratégico" pra usar suas palavras. Portanto, não fixa, mas importante na disputa política desde o feminismo. Também quando falamos do cuidado como uma atribuição das mulheres, além do risco da essencialização, há o risco de, no afã de libertar as mulheres de todas as atribuições que lhes foram historicamente impostas, tanto pela igreja, pelo Estado e pelos homens, esvaziar de importância o cuidado em si. O que pretendemos aqui é propor uma reflexão sobre a hipótese que levantamos acerca das políticas de combate ao novo coronavírus terem sido experiências de políticas escalares do cuidado, para além da casa, como uma política de Estado.

Existem algumas experiências importantes que podem ser pistas para essa consideração, como, por exemplo, aquilo que a feminista Silvia Federici $(2019,2020)$ chama da política dos comuns. É possível ver isso no chamado feminismo descolonial com Lugones (2010) e, também, no feminismo ecossocialista ou ecofeminista em Mies e Shiva (1997), por exemplo. No entanto, não se tratam de experiências que tenham um caráter nacional, são experiências até mais relevantes no sentido de proporem novas possibilidades de arranjos político-geográficos do mundo, são iniciativas com caráter mais emancipatório do que o arranjo do Estado-Nação. Em contrapartida, até pelas formas de poder instituídas, tais experiências sofrem com a invisibilidade e, consequentemente, sofrem com a dificuldade diária de se manterem vivas e potentes e, por isso, muitas vezes incapazes de construir relações políticas escalares.

É nesse sentido de potencializar as experiências de muitas mulheres no mundo, sobretudo nos países periféricos ${ }^{3}$, que contam com baixa representatividade política dessas mulheres fortes e potentes, que escrevemos esse texto. Mulheres que desafiam uma estrutura agrária injusta porque precisam alimentar suas famílias, que desafiam o controle da água pelas multinacionais, porque precisam dar de beber aos seus filhos, que desafiam às tentativas persistentes de fragilização das redes de apoio nas periferias urbanas das grandes cidades, e continuam cuidando dos idosos e das crianças, a despeito de todo o seu desgaste com jornadas duplas ou triplas de trabalho. Mulheres que atuam, muitas delas associadas aos movimentos

\footnotetext{
${ }^{3}$ Não cabe ao escopo desse texto desenvolver a ideia de periferia, fizemos isso num outro texto cuja referência se segue para uma melhor compreensão do que para nós define a periferia ou a periferização da vida como uma potência transgressora às imposições do centro. Vide Biteti, Mariane e Moraes, Marcelo (2019). 
sociais, também por meio de uma política escalar, mas de outra natureza, naquilo que Grandi (2015) chama de escalarização. Um modo de construção social da escala em que o cuidado do lar, da comunidade e da cidade se articulam à dinâmica da vida, na produção do espaço (LEFEBVRE, 2006).

Se o Estado neoliberal provoca uma exploração ainda maior das mulheres, e usa isso como forma de garantir processos de reprodução do capital, como tão bem nos demonstra Fraser (2019), desejo aqui dizer que, se essa experiência política bem sucedida nos países do "Norte" (usado aqui metaforicamente), realizada por mulheres escolhidas como suas representantes, terá sido certamente uma projeção em escala nacional de uma ética e de uma política feminina do cuidado, eis um espaço a ser disputado por nós, mulheres das margens, no campo e na cidade. Sendo disputado como parte de uma luta em que o cuidado do lar possa, a partir do que Marston (2000) chama de "um salto de escala", vir a ser um cuidado com o planeta, numa luta ecológica. E que o cuidado com a comunidade tenha, na mesma perspectiva escalar, um propósito anticapitalista. E que, por fim, a valorização e o reconhecimento das lutas das mulheres das margens, tenham um sentido antissexista, anticolonial e antirracista. Eis aí um sentido progressista do devir-mulher.

Assim, diante da inevitabilidade da disseminação do vírus, abre-se uma questão para o feminismo e para a política que nos parece ser um impasse, mas cuja possibilidade de superação pode nos apresentar um horizonte político interessante. Se as medidas tomadas pelas líderes mulheres não são vistas por elas mesmas como parte de uma política feminista, ficaremos com a intuição e a interpretação de que terá sido, mas sem a confirmação do que pode vir a ser. Se diante disso, também não conseguirmos enxergar as experiências do cuidado vivenciadas pelas mulheres das margens, como práticas de margear, seja em seus lares, seja na comunidade por meio dos movimentos sociais, seja nos terreiros do candomblé ou nas comunidades indígenas, como algo relevante para o feminismo sob o julgo da essencialização, perderemos a oportunidade de alçá-las ao protagonismo político como uma pauta feminista emancipatória. Desejamos, portanto, que o combate à Covid-19 possa evidenciar, como uma de suas marcas principais, que o modo de estar mulher no mundo possa convocar a um outro mundo possível, em que o cuidado de si seja um cuidado do outro, em todas as suas formas de vida: orgânica, inorgânica e humana. 


\section{REFERÊNCIAS BIBLIOGRÁFICAS:}

BITETI, M.; MORAES, M. Vidas y saberes periféricos como potencias transgresoras. Revista de Investigación en Geografía. Cidade do México, Tlalli, 2019.

DELEUZE, G.; GUATARRI, F. O Anti-Édipo. São Paulo: Editora 34, 2011.

FEDERICI, S. O ponto zero da revolução: trabalho doméstico, reprodução e luta feminista. Tradução Coletivo Sycorax. São Paulo: Editora Elefante, 2019.

Mulheres e caça às bruxas: da Idade Média aos dias atuais. Tradução de Heci Regina Candiani. São Paulo: Boitempo Editorial, 2019.

FRASER, N. Feminismo, capitalismo e a astúcia da história. In: HOLLANDA, H. B. (org.) Pensamento feminista: conceitos fundamentais. Rio de Janeiro: Bazar do Tempo, p. 25-48, 2019.

GRANDI, M. da S. A construção escalar da ação no movimento dos sem-teto. Tese (Doutorado em Geografia) - PPGG/Universidade Federal do Rio de Janeiro. Rio de Janeiro, 2015.

LEFEBVRE, H. A produção do espaço. Tradução não-oficial de Doralice Barros Pereira e Sérgio Martins. Do original: La production de l'espace. 4e éd. Paris: Éditions Anthropos, 2000. Primeira versão: início - fevereiro, 2006.

LUGONES, M. Hacia um feminismo descolonial. Revista Hypatia, v. 25, n. 4, 2010.

MARSTON, S. A. The social construction of scale. Progress in Human Geography, v. 20, n. 2, p. 219-242, 2000.

MBEMBE, A. Crítica da razão negra. Lisboa: Antígona, 2017.

MIES, M.; SHIVA, V. Ecofeminismo. Instituto Piaget, 1997. 
MOHANTY, C. T. de. Bajo los ojos de occidente: Academia Feminista y discurso colonial. Descolonizando el feminismo: teorías y prácticas desde los Márgenes. Madrid: Editora Cátedra, 2008.

MOREIRA, R. O pensamento geográfico brasileiro, vol. 1 - As matrizes clássicas. Rio de Janeiro: Editora Contexto, 2008.

RODRIGUEZ ENRÍQUEZ, C. Economía feminista y economia del cuidado: aportes conceptuales para el estúdio de la desigualdade. Revista Nueva Sociedad, n. 256, marzo-abril de 2015.

SPIVAK, G. C. Interview with Angela McRobbie. Block (10), p.5-9, 1985.

Quem reivindica alteridade? In: HOLLANDA, H. B. (Org.). Pensamento feminista: conceitos fundamentais. Rio de Janeiro: Bazar do Tempo, p. 251-270, 2019. 